\title{
HCV Elimination Campaign and Risk Factors of HCV Infection in Arkhangai Province in Mongolia
}

\section{Amgalan Byambasuren', Naranzul Nyamsuren'2, Suvd Batbaatar', Ariun-Erdene Erdenechuluun', Byambatsogt Erdenebat ${ }^{1}$, Gandiimaa Riimaadai ${ }^{3}$, Enkhjargal Altangere ${ }^{2 *}$}

${ }^{1}$ General Hospital of Arkhangai Province, Arkhangai, Mongolia

${ }^{2}$ Academy of Medical Professionals, Ulaanbaatar, Mongolia

${ }^{3}$ Health Department of Arkhangai Province, Arkhangai, Mongolia

Email: *ajargal8@gmail.com

How to cite this paper: Byambasuren, A., Nyamsuren, N., Batbaatar, S., Erdenechuluun, A.-E., Erdenebat, B., Riimaadai, G. and Altangerel, E. (2019) HCV Elimination Campaign and Risk Factors of HCV Infection in Arkhangai Province in Mongolia. Open Journal of Epidemiology, 9, 144-155. https://doi.org/10.4236/ojepi.2019.92013

Received: February 26, 2019

Accepted: May 14, 2019

Published: May 17, 2019

Copyright $\odot 2019$ by author(s) and Scientific Research Publishing Inc. This work is licensed under the Creative Commons Attribution International License (CC BY 4.0).

http://creativecommons.org/licenses/by/4.0/

\begin{abstract}
Background: Most viral hepatitis deaths in 2015 were due to chronic liver disease (720,000 deaths due to cirrhosis) and primary liver cancer (470,000 deaths due to hepatocellular carcinoma). Mongolia has a relatively high sero-prevalence of HCV nationally, approximately 6\% (CDA Foundation/Polaris Observatory). Mongolia has a large burden of viral hepatitis, especially chronic hepatitis B virus (HBV) and hepatitis C virus (HCV) infections, which are associated with cancer and cirrhosis. Methods: All adults aged $40-65$ years being tested for anti-HCV antibodies during the campaign of Arkhangai province. Risk assessment survey questionnaire that includes about behavioral and clinical factors potentially associated with HCV infection was used for optioning data. Statistical analysis that was done using SPSS version 21 was used for data analyzed. The relevant parametric and nonparametric tests were used for data analysis. Result: All 17,601 surveyed of individuals were tested for HCV by using ELISA test for detecting the anti-HCV Ab; 3289 of them were positive and 3049 of them had detected a viral load test. Most of screened population was female $(9095,52.0 \%)$, mainly herdsman (7206, $40.9 \%)$, married $(15,425,87.6 \%)$, educated secondary level school $(11,997$, $68.2 \%)$ and aged between $(9289,52.8 \%)$. Significantly high number of female $(60.6 \%)$, retired people (31.4\%), single (13.8\%) and people aged 55 - 59 years (21.6\%) were infected more HCV-positive than other groups. Patients with HCV were more likely than uninfected individuals to have undergone any kind of surgery, wound and bloodletting treatment in life time. In addition, individual's job plays important role to get infected with HCV. Only 914 (5.2\%) individuals were reported that had no risk factors. 16.6 percent of screened individual were reported they had at least 3 types of risk factors. In to-
\end{abstract}


tal 10,524 individuals were reported that they had more than 4 risk factors to possibility to getting infected with HCV. Conclusion: In total, 19.5 percent of screened individuals had anti-HCV antibody, and most of them was not known not only mothers and sexual partners but also own infection to HCV. Mongolian prevalence of anti-HCV was relatively high. As would be predicted based on accepted risk factors, HCV-positive participants were more likely to have used injection at the non-medical environment, and had any kind of dental procedure, received blood transfusion, been shared needles/injection at the non-hospital environment. Also variety of personal behaviors like having any kind of tattoos influenced significantly to infected to HCV.

\section{Keywords}

HCV, Elimination Campaign, Risk Factors of HCV, Mongolia

\section{Background}

Most viral hepatitis deaths in 2015 were due to chronic liver disease (720,000 deaths due to cirrhosis) and primary liver cancer (470,000 deaths due to hepatocellular carcinoma). Globally, in 2015, estimated 257 million people were living with chronic $\mathrm{HBV}$ infection, and 71 million people with chronic $\mathrm{HCV}$ infection [1]. Due to the fact that acute HCV infection is usually asymptomatic, few people are diagnosed during the acute phase. In those people who go on to develop chronic HCV infection, the infection is also often undiagnosed, because the infection remains asymptomatic until decades after infection when symptoms develop secondary to serious liver damage [2].

Mongolia has a relatively high sero-prevalence of HCV nationally, approximately 6\% (CDA Foundation/Polaris Observatory). Mongolia has a large burden of viral hepatitis, especially chronic hepatitis B virus (HBV) and hepatitis $\mathrm{C}$ virus $(\mathrm{HCV})$ infections, which are associated with cancer and cirrhosis. Chronic $\mathrm{HBV}$ infection is acquired in early childhood in Mongolia, while HCV and hepatitis delta virus (HDV) transmission is healthcare related. Mongolia also has the highest and increasing rate of liver cancer and mortality from liver cancer in the world. Cancer is the second most common cause of death in Mongolia and liver cancer is responsible for $44 \%$ of all cancers. Chronic hepatitis B and C infections are responsible for $95 \%$ of liver cancers in the country [3].

Differences in past $\mathrm{HCV}$ incidence and current $\mathrm{HCV}$ prevalence, together with the generally protracted nature of HCV disease progression, have led to considerable diversity in the burden of advanced liver disease in different countries. Countries with a high incidence of $\mathrm{HCV}$ or peak incidence in the recent past will have further escalations in $\mathrm{HCV}$-related cirrhosis and hepatocellular carcinoma (HCC) over the next two decades. The disease progression of chronic $\mathrm{HCV}$ infection often accelerates after 20 years of infection, with lifestyle factors key drivers of hepatic fibrosis [4].

Mongolia is a lower-middle-income country located in Central Asia and bor- 
dered by Russia and China. Mongolia is unique as it is one of the most sparsely populated countries in the world with 1.9 people per square kilometer [5]. The very low population density and harsh climate make communication, transport, and economic development challenging, thereby complicating health service provision in this country [6].

Arkhangai is one of the 21 provinces of Mongolia, is located slightly west of the country center, covers 21,367 sq.mi and has about 90,000 people living in 19 rural townships (sums). Average life expectancy of resident is 71.08. In total, 27,125 household was inhabited in this province. The province center located $650 \mathrm{~km}$ away from the capital city Ulaanbaatar and each township is located within $280 \mathrm{~km}$ from the provincial center some of them has off-road to reach soum center. The living condition of most household is indoor burning traditional ger dwellings. Internal migration out of province is steadily increased since 2006. From 2011 to 2017, total fertility rate has increasing reached from 2.69 to 2.89 . The main field of economy in the province is agriculture, predominantly animal husbandry. According to 2017, the province has home to 5,290,300 domestic animals: goats, sheep, horses and camels [7].

According to survey Baatarkhuu et al. 2008, prevalence of viral C hepatitis is 16.7 percent [8]. After receiving a donation of HCV diagnostic commodities and drugs, in 2016-2017 the Arkhangai province in Mongolia created an HCV elimination campaign among adults' ages 40 - 65 years. The local health department assembled an HCV screening and treatment plan, guidelines, health facility staff trainings, and a public awareness campaign.

Chronic untreated HCV infection progresses to conditions such as cirrhosis and hepatocellular carcinoma, which eventually lead to death. Despite an overall decline in new infection incidence globally, mortality due to chronic HCV is still high and may increase in coming years due to existing high infection rates and lack of connection to diagnosis and treatment [9] [10].

Jos et al. 2002 developed a mathematic model to estimate the probability of virus transmission by blood transfusion when NAT screening methods are used for virologic safety testing. This is a proper mathematic model for the calculation of residual infection risk by blood transfusion helps understand the impact of introducing new NAT methods for blood safety testing which is also needed in Mongolian case [11].

\section{Ethical Considerations}

The survey methodology was reviewed and got approval from the Mongolian National University of Medical Sciences Ethical Committee on the $17^{\text {th }}$ February, 2017, \# No. 2017/3-2017/02.

\section{Methods}

\subsection{Study Population}

All adults ages 40 - 65 years being tested for anti-HCV antibodies during the 
campaign of Arkhangai province.

\subsection{Data Collection and Duration}

The screening campaign took place from December 2016 to November 2017, with treatment and follow-up through November 2016 to February 2017 (the coldest season of the year average temperature is $-20^{\circ} \mathrm{C}$ ). During the campaign, 17,601 individuals out of 21,700 population (aged between 40 and above) were screened for anti-HCV antibodies, representing approximately $81.1 \%$ of the population ages 40 - 65 years.

\subsection{Survey Instrument}

Based on a literature review regarding HCV risk factors, we developed a risk assessment survey questionnaire that includes about behavioral and clinical factors potentially associated with $\mathrm{HCV}$ infection. Information obtained from all the participants included age, race, sex, education and income levels. The questionnaire also included risk factors (e.g., sharing needs and syringes, history of surgery, usage of blood transfusion, and others). Most questions posed in a yes/no format.

The patient medical record card was created during the treatment period of time and patients who tested positive but didn't meet the criteria for hepatitis $\mathrm{C}$ treatment brought to the attention of the expert's team from tertiary level hospital to determine if further hepatitis $\mathrm{C}$ management was possible.

\subsection{Statistical Analysis}

Statistical analysis was done by using SPSS version 21 (SPSS Inc., Chicago, IL, USA) and used for data analysis. Collected data exported from MS Excel 2010 to SPSS 21.0 software's database and each information analyzed thoroughly. All parameters of survey result was calculated using the parameters of averages and frequency. The relevant parametric and nonparametric tests as follows: Mann-Whitney U test, Kruskal-Wallis test and ANOVA tests were used to compare mean and median parameters, Chi square test was used to compare categorical variables, in order to determine normality of the variance we used the Kolmogorov-Smirnov test. Frequencies and percentages was calculated to describe each components of the testing, treatment cascade and differences between groups (gender, risk factors, presence of HCV and etc.) was calculated with $95 \%$ confidence intervals (95\% CI). In order to evaluate some possible risk factors for the spread of hepatitis $\mathrm{C}$ infection we used multiple logistic regression analysis. No any data were excluded from this analysis.

\section{Result}

All 17601 surveyed of individuals were tested for HCV by using ELISA test for detecting the anti-HCV Ab, from them 3289 individuals were positive and 3049 of them had detected viral load test. Also we had analyzed HBsAg among HCV 
positive patients and 236 (7.2\%) of them were determined HBsAg.

Table 1 shows socio-economic characteristics and HCV risk factors of the liver disease by HCV status. Most of screened population was female (9095, $52.0 \%)$, mainly herdsman (7206, 40.9\%), married (15,425, 87.6\%), educated secondary level school $(11,997,68.2 \%)$ and aged between $(9289,52.8 \%)$.

Significantly high number of female $(60.6 \%)$, retired people $(31.4 \%)$, single (13.8\%), and people aged 55 - 59 years (21.6\%) were more HCV-positive than other groups. As expected HCV-positive patients were by 4 year older than the HCV-negative people and they numbers of risk factors were also higher than the HCV-negative people. Annual income level was similar in both HCV positive and negative group of people.

As would be predicted based on accepted risk factors, HCV-positive participants were more likely to have used injection at the non-medical environment, had any kind of dental procedure, received blood transfusion, been shared needles/injection at the non-hospital environment. Also variety of personal behaviors like having any kind of tattoos influenced significantly to infected to HCV.

Patients with HCV were more likely than uninfected individuals to have undergone any kind of surgery, wound and bloodletting treatment in life time. In addition, individual's job plays important role to get infected with HCV.

In the logistic regression model, a separate indicator variables were included. The age of individuals was the strongest risk factor (age group 40 - 44 vs. 45 - 49 $(\mathrm{OR}=3.26 ; 95 \% \mathrm{CI} 2.87$ - 3.70), age group $40-44$ vs. $50-54(\mathrm{OR}=3.03$; $95 \% \mathrm{CI}$ 2.67 - 3.45), age group 40 - 44 vs. 55 - $59(\mathrm{OR}=2.45 ; 95 \%$ CI 2.15 - 2.79) and age group 40 - 44 vs. $60 \leq(\mathrm{OR}=1.39 ; 95 \% \mathrm{CI} 1.22-1.59)$. Other predictors included a gender $(\mathrm{OR}=1.45 ; 95 \% \mathrm{CI}, 1.34-1.58)$, having any kind of surgery in life time $(\mathrm{OR}=1.42 ; 95 \% \mathrm{CI}, 1.302-1.55)$, history of blood transfusion $(\mathrm{OR}=1.69 ; 95 \%$ CI 1.48 - 1.94), being used bloodletting treatment (OR $=1.17 ; 95 \% \mathrm{CI}, 1.06$ $1.29)$, and having any kind of tattoos $(\mathrm{OR}=1.16 ; 95 \% \mathrm{CI} 1.05-1.29)$. As follows the model of the prediction of HCV infection:

$$
\begin{gathered}
\text { HCV positive }=-0.0657+0.192 \times \text { Dental procedure }+0.215 \times \text { Tattoos } \\
+0.225 \times \text { Lancet for bleeding }+0.498 \times \text { Surgery }+0.474 \times \text { Work } \\
\text { with shark items }+0.538 \times \text { Blood transfusion }+1.069 \times \text { Age group }(1) \\
(40-44 \text { age vs. } 45-49 \text { age })+1.124 \times \text { Age group }(2)(40-44 \text { vs. } 50-54) \\
+0.825 \times \text { Age group }(3)(40-44 \text { vs. } 55-59)+0.258 \\
\quad \times \text { Age group }(4)(40-44 \text { vs. } 60 \text { and above }) .
\end{gathered}
$$

One third of screened individuals (2556,77.7\%) were not aware about own HCV infection status. Only 22.3 percent of (733) individuals were knew about own HCV infection before screening, and slightly high numbers of female HCV positive patients were aware about self and mother's HCV infection status. While, male individuals were significantly more knew about partner's HCV infection status (Figure 1).

In the questionnaire, all individuals were asked to describe their risk factors. Only 914 (5.2\%) individuals were reported that had no risk factors. 16.6 percent 
Table 1. General characteristics of screened individuals.

\begin{tabular}{|c|c|c|c|c|}
\hline Study population characters & $\begin{array}{c}\text { HCV positive } \\
\text { number (\%) } \\
\mathrm{N}=3289\end{array}$ & $\begin{array}{c}\text { HCV negative } \\
\text { number (\%) } \\
\text { n }=14312\end{array}$ & $\begin{array}{l}\text { Total number }(\%) \\
n=17601\end{array}$ & $\mathrm{P}$-value \\
\hline \multicolumn{5}{|l|}{$\operatorname{Sex}^{*}$} \\
\hline Male & $1289(39.4)$ & $7113(50.0)$ & $8402(48.0)$ & $<0.001$ \\
\hline Female & $1980(60.6)$ & $7115(50.0)$ & $9095(52.0)$ & \\
\hline \multicolumn{5}{|l|}{ Employment status ${ }^{*}$} \\
\hline Employed & $573(17.4)$ & $2539(17.7)$ & $3112(17.7)$ & \multirow{7}{*}{$<0.001$} \\
\hline Private business & $310(9.4)$ & $1347(9.4)$ & $1657(9.4)$ & \\
\hline Retired & $1032(31.4)$ & $2395(16.7)$ & $3427(19.5)$ & \\
\hline Herdsman & $1007(30.6)$ & $6199(43.3)$ & $7206(40.9)$ & \\
\hline Unemployed & $164(5.0)$ & $1046(7.3)$ & $1210(6.9)$ & \\
\hline Not working due to health & $183(5.6)$ & $702(4.9)$ & $885(5.0)$ & \\
\hline Unknown (missing) & $20(0.6)$ & $84(0.6)$ & $104(0.6)$ & \\
\hline \multicolumn{5}{|l|}{ Marital status* } \\
\hline Single & $454(13.8)$ & $1722(12.0)$ & $2176(12.4)$ & \multirow[t]{2}{*}{0.005} \\
\hline Married & $2835(86.2)$ & $12,590(88.0)$ & $15,425(87.6)$ & \\
\hline \multicolumn{5}{|l|}{ Educational level } \\
\hline Uneducated & $60(1.8)$ & $334(2.3)$ & $394(2.2)$ & \multirow{7}{*}{0.41} \\
\hline Low & $374(11.4)$ & $1731(12.1)$ & $2105(12.0)$ & \\
\hline Low secondary & $1049(31.9)$ & $4557(31.8)$ & $5606(31.9)$ & \\
\hline High secondary & $1229(37.4)$ & $5162(36.1)$ & $6391(36.3)$ & \\
\hline Collage & $295(9.0)$ & $1253(8.8)$ & $1548(8.8)$ & \\
\hline High & $268(8.1)$ & $1216(8.5)$ & $1484(8.4)$ & \\
\hline Master and $\mathrm{PhD}$ & $14(0.4)$ & $59(0.4)$ & $73(0.4)$ & \\
\hline \multicolumn{5}{|l|}{ Age group ${ }^{*}$} \\
\hline $40-44$ & $660(20.1)$ & $4231(29.6)$ & $4891(27.8)$ & \multirow{5}{*}{$<0.001$} \\
\hline $45-49$ & $628(19.1)$ & $3770(26.3)$ & $4398(25.0)$ & \\
\hline $50-54$ & $633(19.2)$ & $3095(21.6)$ & $3728(21.2)$ & \\
\hline $55-59$ & $711(21.6)$ & $1926(13.5)$ & $2637(15.0)$ & \\
\hline $60 \leq$ & $657(20.0)$ & $1290(9.0)$ & $1947(11.1)$ & \\
\hline Median age in years $\pm \mathrm{IQR}^{*}$ & $52 \pm 12$ & $48 \pm 10$ & $49 \pm 11$ & $<0.001$ \\
\hline $\begin{array}{l}\text { Median monthly income in } \\
\text { tug rugs } \pm \mathrm{IQR}^{*}\end{array}$ & $\begin{array}{c}250,000.00 \pm \\
300,000.00\end{array}$ & $\begin{array}{c}250,000.00 \pm \\
300,000.00\end{array}$ & $\begin{array}{c}250,000.00 \pm \\
327,750.00\end{array}$ & $<0.001$ \\
\hline \multicolumn{5}{|l|}{$\mathrm{HCV}$ risk factors } \\
\hline $\begin{array}{c}\text { Median No of risk factors } \pm \\
\text { IQR }^{*}\end{array}$ & $5 \pm 16$ & $4 \pm 14$ & $4 \pm 16$ & $<0.001$ \\
\hline Dental procedure* & $2536(77.1)$ & $10453(73.0)$ & $12989(73.8)$ & 0.000002 \\
\hline Cosmetic procedure & $555(16.9)$ & $1911(13.4)$ & $2466(14.0)$ & $<0.001$ \\
\hline Wound treatment* & $1091(33.2)$ & $3908(27.3)$ & $4999(28.4)$ & $<0.001$ \\
\hline Tattoo* & $834(25.4)$ & $2833(19.8)$ & $3667(20.8)$ & $<0.001$ \\
\hline Bloodletting treatment ${ }^{*}$ & $650(19.8)$ & $2172(15.2)$ & $2822(16.0)$ & $<0.001$ \\
\hline Sharing shaving device & $100(8.1)$ & $519(7.6)$ & $619(7.7)$ & 0.551 \\
\hline Sharing toothbrush & $112(3.4)$ & $574(4.0)$ & $686(3.9)$ & 0.106 \\
\hline $\begin{array}{c}\text { Injection at non } \\
\text { hospital/sharing needles* }\end{array}$ & $3079(93.6)$ & $13,060(91.3)$ & $16,139(91.7)$ & 0.00001 \\
\hline
\end{tabular}




\section{Continued}

\begin{tabular}{ccccc}
\hline Had any kind of surgery & $1652(50.3)$ & $5520(38.6)$ & $7172(40.8)$ & $<0.001$ \\
Hemodialysis & $21(0.6)$ & $66(0.5)$ & $87(0.5)$ & 0.19 \\
$\begin{array}{c}\text { Contacting and using sharps } \\
\text { and needles* }\end{array}$ & $299(9.1)$ & $709(5.0)$ & $1008(5.7)$ & $<0.001$ \\
\hline
\end{tabular}

${ }^{*} \mathrm{p}<0.005$.

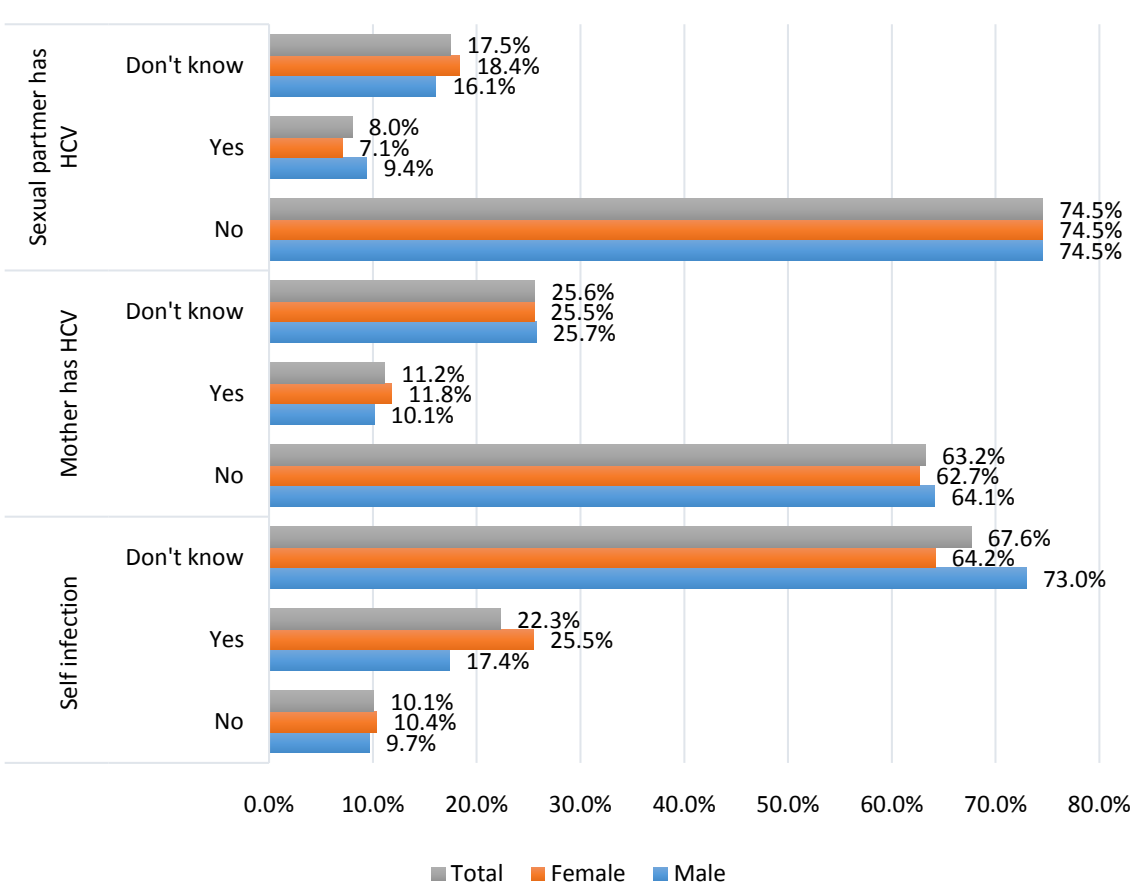

Figure 1. Percentage of HCV positive patient about awareness on self, mothers and partners $\mathrm{HCV}$ positive status by gender.

of screened individual were reported they had at least 3 types of risk factors. In total 10524 individuals were reported that they had more than 4 risk factors to possibility to getting infected with HCV (Table 2).

In comparison, Table 3 shows the result of the logistic regression model on numbers of risk factors. The strongest numbers of risk factors were two $(\mathrm{OR}=$ 3.23 ; $95 \%$ CI $2.54-4.11)$ to three $(\mathrm{OR}=2.30 ; 95 \%$ CI 1.99 - 2.66) risk factors.

\section{Discussion}

Asymptomatic patients with HCV infection identified through screening program could benefit not only from treatment but also from other interventions such as counseling to maintain health and avoid risk behaviors. This might prevent the spread of infection and result in significant public health benefits [12].

Thus, this study aimed to reveal anti-HCV antibody though macro screening among all aged 40 - 65 in Arkhangai, in Mongolia. In total, 19.5 percent of screened individuals were had anti-HCV antibody, and most of them were not known not only mothers and sexual partners but also own infection to $\mathrm{HCV}$. 
Table 2. Number of risk factors of HCV positive patient by gender.

\begin{tabular}{cccc}
\hline No of risk factors & $\begin{array}{c}\text { Male, HCV positive } \\
\text { number (\%), } \mathrm{n}=1294\end{array}$ & $\begin{array}{c}\text { Female, HCV positive } \\
\text { number (\%), } \mathrm{n}=1995\end{array}$ & $\begin{array}{c}\text { Total, HCV positive } \\
\text { number (\%), } \mathrm{n}=3289\end{array}$ \\
\hline 0 & $72(5.6)$ & $72(3.6)$ & $144(4.4)$ \\
1 & $39(3.0)$ & $45(2.3)$ & $84(2.6)$ \\
2 & $145(11.2)$ & $183(9.2)$ & $328(10.0)$ \\
3 & $182(14.1)$ & $313(15.7)$ & $495(15.1)$ \\
4 & $204(15.8)$ & $214(10.7)$ & $418(12.7)$ \\
5 & $176(13.6)$ & $264(13.2)$ & $440(13.4)$ \\
6 & $174(13.4)$ & $202(10.1)$ & $376(11.4)$ \\
7 & $136(10.5)$ & $189(9.5)$ & $325(9.9)$ \\
$\geq 8$ & $166(12.8)$ & $513(25.7)$ & $679(20.6)$ \\
p value & $<0.001$ & $<0.001$ & $<0.001$ \\
\hline
\end{tabular}

Table 3. Odds ratio of HCV logistic regression model that considers the number of risk factors reported.

\begin{tabular}{ccc}
\hline Numbers of risk factors & Odds ratio & $95 \%$ CI \\
\hline 1 vs. 0 & 1.93 & $1.59-2.36$ \\
2 vs. 0 & 3.23 & $2.54-4.11$ \\
3 vs. 0 & 2.30 & $1.99-2.66$ \\
4 vs. 0 & 1.77 & $1.55-2.02$ \\
5 vs. 0 & 1.84 & $1.61-2.11$ \\
6 vs. 0 & 1.49 & $1.30-1.71$ \\
7 vs. 0 & 1.34 & $1.16-1.55$ \\
$8 \leq$ vs. 0 & 1.19 & $1.02-1.39$ \\
\hline
\end{tabular}

Nagelkerke $\mathrm{R}^{2}=0.021, \mathrm{p}<0.001$.

Those findings were similar with many other researches that most people do not know their hepatitis status. Cohen et al., 2007 had conducted a cohort of 3768 women who had or were at risk for HIV infection. About one-fourth of those with chronic HCV infection were not aware of their infection status [13]. WHO reported that the simple and effective hepatitis testing strategies and tools are lacking, with less than 5 percent of people with chronic hepatitis infection knowing their status. For this reason, diagnosis often occurs late and appropriate tests to assess liver disease and guide treatment decisions, including when to start treatment, are seldom available [14].

Ludmila [15] et al. were figured out HCV prevalence of 11 countries. The $\mathrm{HCV}$ prevalence data show a general national population anti-HCV prevalence range of 1.5 to 7.5, with Kazakhstan and Georgia having the lowest and highest rates, respectively. Using 2016 population figures from national sources, total numbers of HCV-positive people are highest in Russia (5.9 million), Uzbekistan (1.8 million) and Ukraine (2.1 million). Prevalence among persons who injects drugs ranges from 22.7 (Tajikistan) to 70 - 95 (Belarus). Since only small studies were available, ranges are shown for Belarus, Georgia, Moldova and Tajikistan. Persons who injects drugs are specified as a key population in nine countries (82); healthcare workers and patients undergoing invasive/hospital-level procedures are specified in three (27). Those countries are post-soviet union which are 
similar with Mongolian condition. Compared to this survey according to our survey findings, Mongolian prevalence of anti-HCV was relatively high.

The major modality of HCV transmission in Mongolia over the past half century has been through parenteral exposure within the formal and informal health sector. The proportion of cases that acquire HCV infection through sexual or vertical transmission is unknown. Injecting drug use is currently very uncommon in Mongolia and does not play a significant role in the transmission of HCV. The two major sero epidemiological surveys for HBV also included HCV serology, and are the most nationally representative sero surveys carried out in Mongolia to date [16] [17] [18].

Age distribution among adults, the prevalence of anti-HCV antibody $(\mathrm{Ab})$ increases with age, with the highest prevalence in both population-based studies seen among persons in birth cohorts from the mid-1950s and earlier, and lowest among persons in the birth cohorts from about 1990 onward [3]. Based on this statement possibilities to get infected risk of older individuals who attended to our survey was relatively high than younger people.

A number of studies indicate that the peak of viral hepatitis transmission was in the 1970s and 1980s before disposable syringes were available in Mongolia. Poor infection control, re-use of syringes in health settings and administering injections at home led to the rapid spread of viral hepatitis [19]. We defined that among people who aged 40-65 had high risk of history of re-use of syringes not only in the hospital but also at non-hospital environment.

Based on survey finding of Hwang et al. 2006 [20] was higher HCV prevalence was independently associated with increasing age, history of injection drug use, blood transfusion before 1991, incarceration. There was no increased risk for HCV or HBV infection in low-risk adults based solely on history of cosmetic procedures or snorting drugs. In our survey, also higher risks were age, blood transfusion, sharing a needs, cosmetic procedures and tattoos. In addition, undergone any surgery in life time, dental procedure, risky hygienic behaviors were also adding a risk to get infected in Mongolia. There are many other researchers were highlighted risk factors of $\mathrm{HCV}$ is age, blood transfusion, tattoos, and cosmetic procedures [21] [22] [23] [24].

David L Thomas [25] et al. was assessed the occupational risk of hepatitis C virus (HCV) infection among dental personnel in North America. Anti-HCV was found in 2.0 percent of oral surgeons and 0.7 percent of general dentists. Anti-HCV was more prevalent in dental personnel who were older, had more years of practice, and had serologic markers of HBV infection and they are confirming high rates of HBV infection among dental personnel. Risk factor that asked in our survey shows working with sharp items is one of main risk factors of HCV among Mongolian health personnel.

Based on WHO recommendation each country should define the specific populations within their country that are most affected by viral hepatitis epidemics and the response should be based on the epidemiological and social con- 
text. We would suggest based on our findings age, gender, having any kind of surgery in life time, being used bloodletting treatment, having any kind of tattoos, and dental procedures are most risky context of HCV infection in Mongolian rural settings.

In many countries, much transmission of hepatitis $B$ virus and hepatitis $C$ occurs in health care settings and therefore specific populations for focused attention include people who have been exposed to viral hepatitis through unsafe blood supplies and unsafe medical injections and procedures. In settings with high hepatitis B prevalence, mother-to-child transmission of hepatitis B is likely to be a major mode of transmission, along with early childhood infection among those who have not been vaccinated. People who inject drugs are at high risk of hepatitis $C$ infection and hepatitis B infection because of the shared use of contaminated injecting equipment and blood. Mobile populations, and people affected by conflict and civil unrest may be at particular risk of all forms of viral hepatitis infection because of their living conditions, lack of access to clean water and safe food and medical services that cannot maintain effective infection control measures. People who will require specific attention include those with co-infections such as: hepatitis B and C combined; viral hepatitis and tuberculosis; and HIV and viral hepatitis.

Our study has several limitations. Although trained physicians were asked screening questions we used self-reported HCV risk factors. In the questionnaire's some of self-reported risk factors are missing. In our study population might not be representative for the population as a whole but could be present whole population aged 40 - 65 in Arkhangai province.

In further cost-effectiveness analysis and public health actions should take into account not only the screening of anti-HCV $(\mathrm{Ab})$ and treatment of HCV infected individuals but also the strategy on prevention of re-infection is essential.

\section{Acknowledgements}

Special thanks to the member of Parliament of Mongolia Mr. Baatarbileg E, Ministry of Health, Arkhangai governing council and the Arkhangai Governor's office for strategic planning and support; to NCCD for their excellent cooperative work. All the residents of Arkhangai province express heartfelt thanks to Gilead Sciences, Inc. USA; LF Asia (Hong-Kong Limited); "Ombol" LLC, General director Tumurbat $\mathrm{B}$, distributor in Mongolia, for all their support and cooperation in making this project possible.

\section{Conflicts of Interest}

The authors declare no conflicts of interest regarding the publication of this paper.

\section{References}

[1] WHO (2018) Global Hepatitis Report, 2017. 
http://apps.who.int/iris/bitstream/handle/10665/255016/9789241565455-eng.pdf?se quence $=1$

[2] WHO (2018) Fact Sheets, Hepatitis C. http://www.who.int/news-room/fact-sheets/detail/hepatitis-c

[3] WHO (2016) Data Viral Hepatitis in Mongolia: Situation and Response 2015. World Health Organization Regional Office for the Western Pacific.

[4] Hajrizadeh, B., Grebely, J. and Dore, G.J. (2013) Epidemiology and Natural History of HCV Infection. Nature Reviews Gastroenterology \& Hepatology, 10, 553-562. https://doi.org/10.1038/nrgastro.2013.107

[5] The World Bank. Population Density (People per sq. km of Land Area). http://data.worldbank.org/indicator/EN.POP.DNST?end=2015\&locations=MN\&sta $\mathrm{rt}=1994$

[6] Davaalkham, J., Unenchimeg, P., Baigalmaa, C., Oyunbileg, B., Tsuchiya, K., Hachiya, A., Gatanaga, H., Nyamkhuu, D. and Oka, S. (2009) High-Risk Status of HIV-1 Infection in the Very Low Epidemic Country, Mongolia, 2007. International Journal of STD \& AIDS, 20, 391-394. https://doi.org/10.1258/ijsa.2008.008376

[7] ASO (2017) Demographic and Social-Economic Brief. http://www.arkhangai.nso.mn

[8] Baatarkhuu, O., et al. (2008) Prevalence and Genotype Distribution of Hepatitis C Virus among Apparently Healthy Individuals in Mongolia: A Population-Based Nationwide Study. Liver International, 28, 1389-1395. https://doi.org/10.1111/j.1478-3231.2008.01820.x

[9] Lozano, R., Naghavi, M., Foreman, K., Lim, S., Shibuya, K., Aboyans, V., et al. (2012) Global and Regional Mortality from 235 Causes of Death for 20 Age Groups in 1990 and 2010: A Systematic Analysis for the Global Burden of Disease Study 2010. The Lancet, 380, 2095-2128.

[10] GBD (2013) Mortality and Causes of Death Collaborators. Global, Regional, and National Age-Sex Specific All-Cause and Cause-Specific Mortality for 240 Causes of Death, 1990-2013: A Systematic Analysis for the Global Burden of Disease Study 2013. The Lancet, 385, 117-171. https://doi.org/10.1016/S0140-6736(14)61682-2

[11] Weusten, J.J., van Drimmelen, H.A. and Lelie, P.N. (2002) Mathematic Modeling of the Risk of HBV, HCV, and HIV Transmission by Window-Phase Donations Not Detected by NAT. Transfusion, 42, 537-548.

https://doi.org/10.1046/j.1537-2995.2002.00099.x

[12] El-Ghitany, E.M., Farghaly, A.G., Abdel Wahab, M.M., Farag, S. and Abd El-Wahab, E.W. (2016) Toward a Simple Risk Assessment Screening Tool for HCV Infection in Egypt. Journal of Medical Virology, 88, 1767-1775. https://doi.org/10.1002/jmv.24520

[13] Cohen, M.H., Grey, D., Cook, J.A., Anastos, K., Seaberg, E., Augenbraun, M., Burian, P., Peters, M., Young, M. and French, A. (2007) Awareness of Hepatitis C Infection among Women with and at Risk for HIV. Journal of General Internal Medicine, 22, 1689-1694. https://doi.org/10.1007/s11606-007-0395-x

[14] Substance Abuse and Mental Health Services Administration (2011) Addressing Viral Hepatitis in People with Substance Use Disorders. Treatment Improvement Protocol (TIP) Series 53. HHS Publication No. (SMA) 11-4656. Substance Abuse and Mental Health Services Administration, Rockville.

[15] Maistat, L., Kravchenko, N. and Reddy, A. (2017) Hepatology, Medicine and Policy, Hepatitis C in Eastern Europe and Central Asia: A Survey of Epidemiology, Treat- 
ment Access and Civil Society Activity in Eleven Countries. Hepatology, Medicine and Policy, 2, 9. https://doi.org/10.1186/s41124-017-0026-z

[16] Baatarkhuu, O., Kim, D.Y., Ahn, S.H., Nymadawa, P., Dahgwahdorj, Y., Shagdarsuren, M., Park, J.Y., Choi, J.W., Oyunbileg, J., Oyunsuren, T. and Han, K.H. (2008) Prevalence and Genotype Distribution of Hepatitis C Virus among Apparently Healthy Individuals in Mongolia: A Population-Based Nationwide Study. Liver International, 28, 1389-1395.

[17] Dashtseren, B., Bold, B., Dashdorj, N. and Yagaanbuyant, D. (2014) P29: Epidemiological Study of Prevalence and Risk Factors for HBV among Apparently Healthy Mongolians. Journal of Viral Hepatitis, 21, 38. https://doi.org/10.1111/jvh.12333_28

[18] Dashdorj, N., Dashtseren, B., Bold, B. and Yagaanbuyant, D. (2014) P5: Epidemiological Study of Prevalence and Risk Factors for HCV among Apparently Healthy Mongolians. Journal of Viral Hepatitis, 21, 23-24.

https://doi.org/10.1111/jvh.12333_4

[19] WHO (2015) Hepatitis: A Crisis in Mongolia. http://www.wpro.who.int/hepatitis/resource/features/mongolia_story/en

[20] Hwang, L.Y., Kramer, J.R., Troisi, C., Bull, L., Grimes, C.Z., Lyerla, R. and Alter, M.J. (2006) Relationship of Cosmetic Procedures and Drug Use to Hepatitis C and Hepatitis B Virus Infections in a Low-Risk Population. Hepatology, 44, 341-351. https://doi.org/10.1002/hep.21252

[21] Mahmud, S., Akbarzadeh, V. and Abu-Raddad, L.J. (2018) The Epidemiology of Hepatitis C Virus in Iran: Systematic Review and Meta-Analyses. Scientific Reports, 8, 150. https://doi.org/10.1038/s41598-017-18296-9

[22] Chaabna, K., Mohamoud, Y.A., Chemaitelly, H., Mumtaz, G.R. and Abu-Raddad, L.J. (2014) Protocol for a Systematic Review and Meta-Analysis of Hepatitis C Virus (HCV) Prevalence and Incidence in the Horn of Africa Sub-Region of the Middle East and North Africa. Systematic Reviews, 3, 146. https://doi.org/10.1186/2046-4053-3-146

[23] Stanaway, J.D., et al. (2016) Te Global Burden of Viral Hepatitis from 1990 to 2013: Findings from the Global Burden of Disease Study 2013. The Lancet, 388, 10-16.

[24] Denniston, M.M., et al. (2014) Chronic Hepatitis C Virus Infection in the United States, National Health and Nutrition Examination Survey 2003 to 2010. Annals of Internal Medicine, 160, 293-300. https://doi.org/10.7326/M13-1133

[25] Thomas, D.L., Gruninger, S.E., Siew, C., Joy, E.D. and Quinn, T.C. (1996) Occupational Risk of Hepatitis C Infections among General Dentists and Oral Surgeons in North America. The American Journal of Medicine, 100, 41-45. https://doi.org/10.1016/S0002-9343(96)90009-1 